\title{
Load distribution method in helicopter blade multibody dynamics system
}

\author{
Anton Didenko ${ }^{1}$, Vladislav Borisenko ${ }^{1}$, and Jose Leoro ${ }^{1, *}$ \\ ${ }^{1}$ Peter the Great St. Petersburg Polytechnic University (SPbPU), 195251 St. Petersburg, Russia
}

\begin{abstract}
The paper focuses on the loads applied to the helicopter blade cross-sections in the multibody dynamics system. The main objective is to simplify the blade aerodynamics calculation and avoid time-consuming CFD methods. For this reason, the way of computing blade aerodynamics is proposed by using multibody dynamics methods with a linear-elastic blade model. As the primary tool for further research, the MCS Adams software package is selected. Splitting the main rotor blade into a finite number of sections, each having its own average value of installation and coning angles, simplifies the calculation. Afterward, expressions for the total flow velocity around the blade section and its angle of attack are obtained through vector operations. This provides a measure of aerodynamic forces acting on each section in its cross-sectional coordinate system. In conclusion, the article provides the formalized method of aerodynamic force distribution between blade sections in the multibody model as well as the correlation between the flow coordinate system and the blade chord coordinate system.
\end{abstract}

\section{Introduction}

Helicopter flight performance determination phase entails a comprehensive approach to main rotor design. However, industry requirements continue to grow in the pursuit of the most balanced solution.

A major problem in such projects is the calculation of loads applied to the helicopter main rotor blade. The requirement is to consider the elasticity parameters, taking into account the simultaneous motion of the blade makes the solution unrealizable by CFD method in a limited time at an accelerated pace. For this reason, we suggest a method for calculating the necessary loads using multibody dynamics (MBD) approach.

The problem of loads application to the elastic blades in the MBD model is the twist of the blade as you move away from the rotation center. Besides that, the angle of the crosssection with respect to the horizontal is changing due to the elasticity of the blade. It is the result of the difference in the lifting forces acting on the blade as a function of the distance from the center of rotation [1]. It leads to the blade deformations and twisting of the crosssections.

\footnotetext{
*Corresponding author: zhilenkovanton@gmail.com
} 
Therefore, to determine the force acting on the cross-section at a particular time, it is necessary to determine the cross-section angle of attack in advance. It depends on the blade installation angle and the vector of the total cross-section velocity, as shown in figure 1.

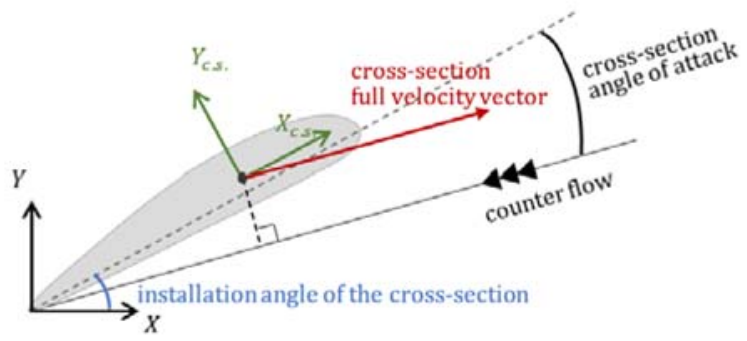

Fig. 1. Blade installation angle determination scheme.

\section{Blade discretization}

Firstly, it is necessary to divide the blade model into a finite number of sections with an average value of the initial installation angle. It will be used in an MBD system of the main rotor. It is vital to consider the following factors to perform the discretization of the blade.

The difference between installation angles of the end faces for each blade section is not greater than $\delta \theta_{\text {max }}$ :

$$
\delta \theta_{\text {max }}=\Delta \theta \cdot 10 \mathrm{~b} \cdot \mathrm{L}^{-1}
$$

where $\Delta \theta$ is the difference between maximum and minimum cross-section installation angles, $\mathrm{b}$ is the section chord, $\mathrm{L}$ is the blade length. This equation was obtained for a specific task during the discussions. It is likely that in any other situation, this equation will have a different form.

The length of the blade section should be limited in length so that when the blade bends, discrepancy between the coning angles in the transverse direction at the outermost faces of the section is not more than some critical value. For instance, in this work, the angle of $1^{\circ}$ was used as a critical value.

With this configuration, it has been found that in order to meet the requirements defined above, it is necessary to split the blade into 10 sections, as shown in figure 2 .

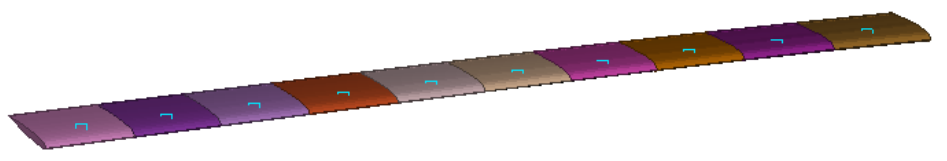

Fig. 2. Blade discretization into sections.

Each of the 10 sections has the following characteristics in the MBD main rotor system: length, average installation angle, and average coning angle.

The elastic characteristics are already set for each section in the MBD model using the modal superposition method [2] for the entire main rotor blade.

In MSC Adams software each section is defined by an oriented marker on the elastic blade. This marker determines the orientation and position of each blade section in space. The length of the sections is determined parametrically using the built-in MSC Adams function defining the distance between two node points. The equation for determining the length of the $i$ section is specified in (2) below. 


$$
\mathrm{L}_{\mathrm{i}}=0,5 \cdot \mathrm{DM}(i+1, i)+0,5 \cdot \operatorname{DM}(i-1, i),
$$

where $\operatorname{DM}(i+1, i)$ is a distance function between section centers $i$ and $i+1, \operatorname{DM}(i-1, i)$ - distance function between centers $i$ and $i-1$.

For the first and the last blade sections length is determined by (3) and (4) respectively.

$$
\begin{gathered}
\mathrm{L}_{1}=\operatorname{DM}(1,2) \\
\mathrm{L}_{\max }=\operatorname{DM}\left(i_{\text {max }}, i_{\text {max }}-1\right)
\end{gathered}
$$

To make such section length dependencies possible it is needed to set section centers in the blade MBD model in advance.

\section{Methodology for determining the velocity and position of the blade section relative to the flow}

The goal is to create a method for conversion of acting on the blade section forces defined in the flow coordinate system into the blade chord coordinate system.

The specific feature of the forces acting on the blade section calculation is the combination of mechanical dependences of the section angle of attack with experimental dependences of the lifting force coefficient.

The following subsections present the procedure for calculating and converting the aerodynamic forces into the blade section coordinate system required for an MBD model.

\subsection{Determination of flow velocity around blade sections in a cross-section plane}

The first step in aerodynamic forces determination process is to determine the total velocity vector of each section of the blade.

The created MBD model allows us to determine the velocity projections of each section on the $\mathrm{X}, \mathrm{Y}$, and $\mathrm{Z}$ axes in the coordinate system associated with the helicopter body. To obtain the flow velocity, we need to take the vector opposite to the one defined in the MBD system. An example of the output flow velocities is shown in figure 3.

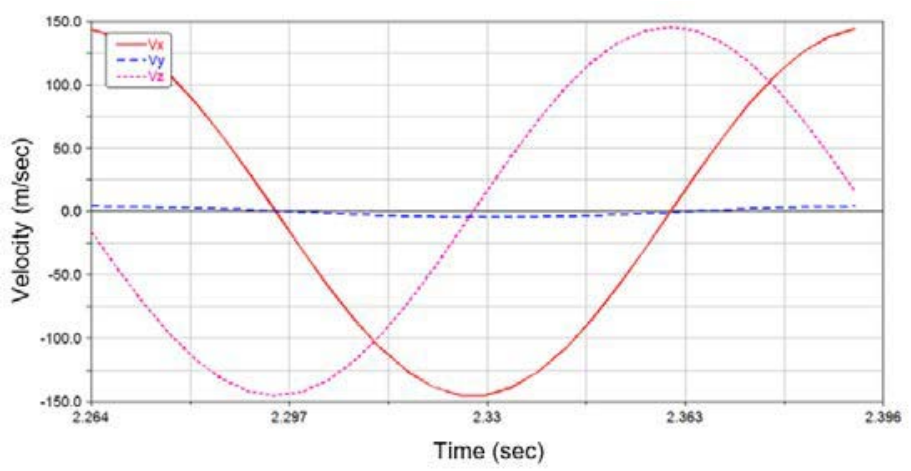

Fig. 3. Output flow velocities for the 7-th section during one blade turn.

The flow vector considers only the rotational motion of the main rotor with respect to the angle of attack. However, it does not consider the motion of the helicopter. As a result, the vector of the total flow velocity around the $i$ blade section is defined as: 


$$
\mathrm{V}_{\mathrm{i}}^{\text {full }}=-\mathrm{V}_{\mathrm{i}}^{\mathrm{MB}}-\mathrm{V}_{\mathrm{h}}
$$

where $\mathrm{V}_{\mathrm{i}}^{\mathrm{MB}}$ - the $i$ section velocity vector, defined in MBD model, $\mathbf{V}_{\mathbf{h}}$ - the helicopter velocity vector. 4.

The full velocity components, considering the helicopter movement, are shown in figure

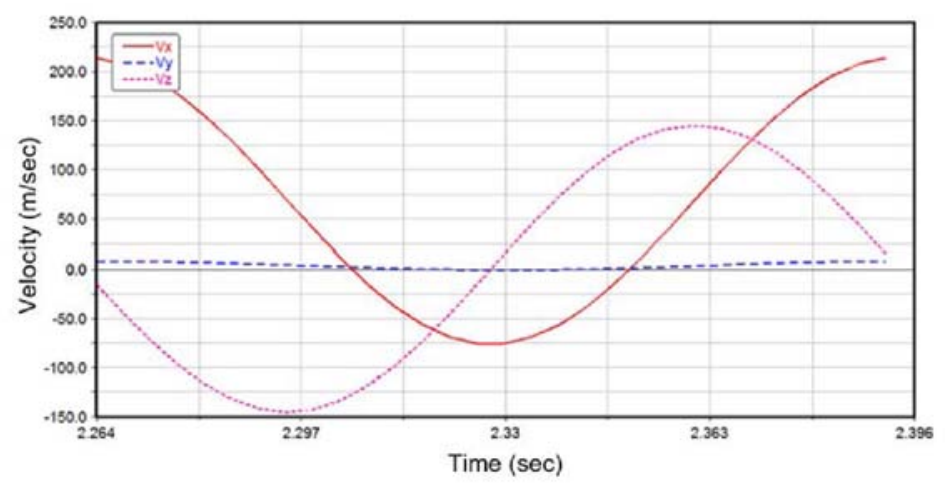

Fig. 4. Full velocity components for the 7-th section during one blade turn.

To determine the flow velocity around the blade section in the cross-section plane, it is necessary to obtain a projection of the velocity vector from the equation (5). To do this, as shown in (6), its component perpendicular to the $i$ section is subtracted from the obtained velocity vector.

$$
V_{i}^{\text {c.s. }}=V_{i}^{\text {full }}-n_{i}\left(V_{i}^{\text {full }} \cdot n_{i}\right) \text {, }
$$

where $\mathrm{V}_{\mathrm{i}}^{\text {c.s. }}$ - velocity vector of the $i$ section projected on the cross-section plane, $\mathbf{n}_{\mathbf{i}}-$ the unit vector perpendicular to the $i$ section.

\subsection{Blade section angle of attack measurement}

The second stage of aerodynamic forces determination process is to determine the blade section angle of attack.

The angle of attack can be found using the information about the projection of the blade section velocity vector on the cross-section plane and each blade section orientation with respect to the helicopter coordinate system will be needed for future analysis.

Euler angles $\alpha, \beta, \gamma$ will be the output data from the MBD model of the blade. These angles define the position of the $i$ blade section coordinate system with respect to the helicopter coordinate system.

The $i$ cross-section coordinate system is chosen so that the $\mathrm{X}$-axis coincides with the blade chord and is pointed in the direction of rotation. The $\mathrm{Z}$-axis is directed perpendicular to the cross-section of the blade section, and the Y-axis is directed upward, perpendicular to the chord.

The resulting Euler angles are used to determine the unit vector $l_{i}$ which is co-directional with the blade chord according to the equation (7):

$$
l_{i}=R \cdot\left(\begin{array}{lll}
1 & 0 & 0
\end{array}\right)^{\mathrm{T}}
$$

$\mathrm{R}$ is the rotation matrix and $\alpha, \beta, \gamma$ are the Euler angles of the $i$ blade section: 


$$
\mathrm{R}=\left(\begin{array}{ccc}
\cos \alpha \cos \gamma-\sin \alpha \cos \beta \sin \gamma & \cos \alpha \sin \gamma+\sin \alpha \cos \beta \cos \gamma & \sin \alpha \sin \beta \\
-\sin \alpha \cos \gamma-\cos \alpha \cos \beta \sin \gamma & \cos \alpha \cos \beta \cos \gamma-\sin \alpha \sin \gamma & \cos \alpha \sin \beta \\
\sin \beta \sin \gamma & -\sin \beta \cos \gamma & \cos \beta
\end{array}\right)
$$

The blade section angle of attack is determined according to the equation (9).

$$
\alpha_{i}=\operatorname{arcos}\left(\frac{\mathrm{V}_{\mathrm{i}}^{\text {c.s. }} \cdot \mathrm{l}_{\mathrm{i}}}{\sqrt{\mathrm{V}_{\mathrm{i}}^{\text {c.S. }} \cdot \mathrm{V}_{\mathrm{i}}^{\text {c.s. }}}}\right)
$$

Figure 5 clearly shows the definition of the angle of attack.

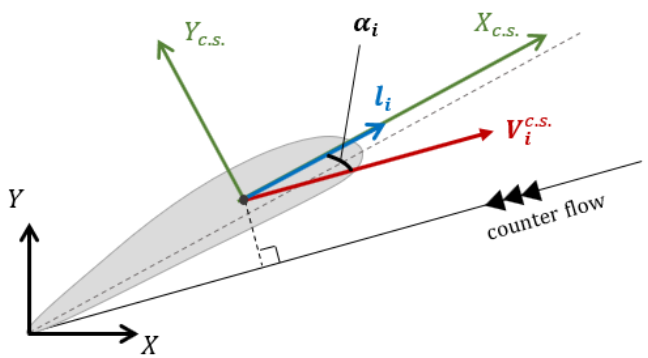

Fig. 5. Cross-section angle of attack definition.

\subsection{Lifting forces and profile drag forces determination acting on the blade section in the flow coordinate system}

The third stage of aerodynamic forces determination process is to calculate the lifting forces and the profile drag forces acting on the blade section. For this purpose, the lift force and profile drag coefficients need to be determined.

Calculation of lifting force coefficients $\mathrm{C}_{\mathrm{ya}}$ and profile drag $\mathrm{C}_{\mathrm{xp}}$ is based on experimental data of profile blowing, which contains dependences of $\mathrm{C}_{\mathrm{ya}}$ and $\mathrm{C}_{\mathrm{xp}}$ on the angle of attack $\alpha$ and flow velocity of the profile (Mach number).

An example of dependence $C_{x p}$ on the profile angle of attack and Mach number is shown below in the table 1 .

\begin{tabular}{|c|c|c|c|c|c|c|c|}
\hline & & \multicolumn{6}{|c|}{ Mach number } \\
\hline & & 0 & 0.1 & 0.2 & 0.3 & 0.4 & 0.5 \\
\hline \multirow{7}{*}{ 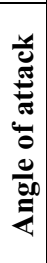 } & -8 & 0.018 & 0.018 & 0.018 & 0.0247 & 0.03 & 0.0352 \\
\hline & -2 & 0.0086 & 0.0086 & 0.0086 & 0.0094 & 0.0089 & 0.0092 \\
\hline & 0 & 0.0065 & 0.0068 & 0.0068 & 0.0079 & 0.0076 & 0.0076 \\
\hline & 2 & 0.0065 & 0.0068 & 0.0068 & 0.0079 & 0.0082 & 0.0084 \\
\hline & 4 & 0.0087 & 0.0087 & 0.0087 & 0.0095 & 0.0107 & 0.012 \\
\hline & 6 & 0.0098 & 0.0098 & 0.0098 & 0.0123 & 0.0135 & 0.0156 \\
\hline & 8 & 0.0145 & 0.0146 & 0.0146 & 0.0159 & 0.0195 & 0.028 \\
\hline
\end{tabular}

Table 1. Dependence $C_{x p}$ on the profile angle of attack and Mach number.

A linear interpolation is made between all points of Mach number and profile angle of attack to make it possible to determine the forces acting on the blade section at any combination of Mach number and profile angle of attack lying in the interval of the experimental data.

Then dependences (10) and (11) are used to determine the lifting loads $\Delta \mathrm{Y}$ and profile drag loads $\Delta \mathrm{X}$ acting on the blade section in the flow coordinate system [3,4-8]. 


$$
\begin{aligned}
& \Delta \mathrm{Y}=\mathrm{C}_{\text {ya }} \mathrm{b} \cdot 0.5 \rho\left|\mathrm{V}_{\mathrm{i}}^{\text {c.s. }}\right|^{2}, \\
& \Delta \mathrm{X}=\mathrm{C}_{\text {xa }} \mathrm{b} \cdot 0.5 \rho\left|\mathrm{V}_{\mathrm{i}}^{\text {c.s. }}\right|^{2},
\end{aligned}
$$

where $\rho$ is the air density and $\mathrm{b}$ is the blade chord.

Further, dependences (12) and (13) are used to determine the lifting forces $\mathrm{F}_{\mathrm{y}}$ and the profile drag forces $\mathrm{F}_{\mathrm{x}}$ acting on the blade section in the flow coordinate system.

$$
\begin{aligned}
& \mathrm{F}_{\mathrm{y}}=\Delta \mathrm{Y} \cdot \mathrm{s}, \\
& \mathrm{F}_{\mathrm{x}}=\Delta \mathrm{X} \cdot \mathrm{s},
\end{aligned}
$$

where $s$ is blade section length.

The resulting forces are determined in the flow coordinate system, as shown in figure 7.

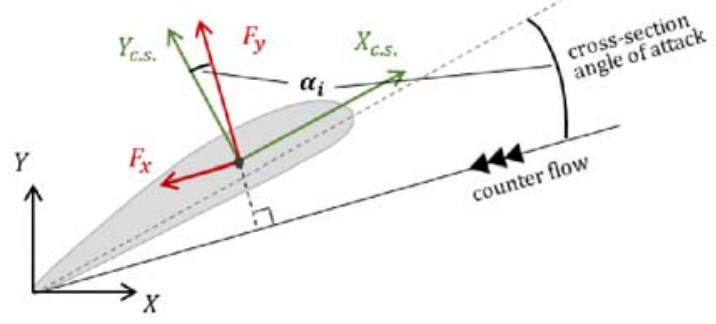

Fig. 7. Resulting forces $F_{x}$ and $F_{y}$ determined in the coordinate system associated with the flow.

However, the MBD model uses the cross-section coordinate system associated with the chord. Therefore, to apply forces on the blade section in the MBD model, the obtained forces must be translated into the local coordinate system of the cross-section.

\subsection{Lifting and drag forces projection into the cross-section coordinate system}

The fourth stage of aerodynamic forces determination process consists of calculating the conversion of the lifting forces and the profile drag forces acting on the section into the profile coordinate system [9-11].

This projection is performed using the dependencies (14) and (15), based on the position of the axes of the profile coordinate system and marked in figure 7.

$$
\begin{gathered}
\mathrm{F}_{\mathrm{y}}^{\text {c.s. }}=\mathrm{F}_{\mathrm{y}} \cos \left(\alpha_{i}\right)+\mathrm{F}_{\mathrm{x}} \sin \left(\alpha_{i}\right) \\
\mathrm{F}_{\mathrm{x}}^{\text {c.s. }}=-\mathrm{F}_{\mathrm{x}} \cos \left(\alpha_{i}\right)+\mathrm{F}_{\mathrm{y}} \sin \left(\alpha_{i}\right)
\end{gathered}
$$

The resulting forces $\mathrm{F}_{\mathrm{y}}^{\mathrm{c} . s .}$ and $\mathrm{F}_{\mathrm{x}}^{\mathrm{c} . s .}$ are transferred to the marker points of the blade section centers in the MBD model of the main rotor. Then the next integration step in the MBD model is calculated, all operations of force calculation are repeated for the new position and velocity of the blade compartments [12-14].

\section{References}

1. C.K. Zioutis, A.I. Spyropoulos, A.P. Fragias, D.P. Margaris, D.G. Papanikas, International Journal of Engineering 3, 521-537 (2010)

2. M.G. Prasad, THEORY OF VIBRATION. Superposition (2001) 
3. M. Karimirad, Comprehensive Renewable Energy 2, 248 (2012)

4. M.O.L. Hansen, J.N. Sørensen, S. Voutsinas, N. Sørensen, H.Aa. Madsen, Progress in Aerospace Sciences, 42, 285-330 (2006)

5. D. Lisitsa, A.A. Zhilenkov, IEEE Conf. of Russian Young Researchers in Electrical and Electronic Engineering (EIConRus) 922 (2017) doi: 10.1109/EIConRus.2017.7910707

6. S. Sokolov, A. Zhilenkov, S. Chernyi, A. Nyrkov, D. Mamunts, Symmetry 11, 236 (2019). https://doi.org/10.3390/sym11020236

7. D.O. Solovev et al, IOP Conf. Ser.: Mater. Sci. Eng. 747, 012076 (2020)

8. A.A. Zhilenkov, I.R. Epifantsev, IEEE Conference of Russian Young Researchers in Electrical and Electronic Engineering (EIConRus) 1032 (2018) doi: 10.1109/EIConRus.2018.8317265

9. A.A. Zhilenkov, IEEE Conference of Russian Young Researchers in Electrical and Electronic Engineering (EIConRus) 400 (2018) doi: 10.1109/EIConRus.2018.8317117

10. A.V. Ivanov, A.A. Zhilenkov, IEEE Conference of Russian Young Researchers in Electrical and Electronic Engineering (EIConRus) 890 (2018) doi: 10.1109/EIConRus.2018.8317231

11. A.I. Borovkov, L.B. Maslov, K.S. Ivanov, E.N. Kovaleva, F.D. Tarasenko, M.A. Zhmaylo, IOP Conf. Ser.: Mater. Sci. Eng. 986, 012034 (2020)

12. A.D. Karpov, A.A. Zhilenkov, D. Lisitsa, IEEE Conference of Russian Young Researchers in Electrical and Electronic Engineering (EIConRus) 887 (2017) doi: 10.1109/EIConRus.2017.7910697

13. A.A. Zhilenkov, D. Denk, IEEE Conference of Russian Young Researchers in Electrical and Electronic Engineering (EIConRus) $1104 \quad$ (2017) doi: 10.1109/EIConRus.2017.7910748

14. B. Dang, A. Zhilenkov, AIP Conf. Proc. 2034, 020007 (2018) https://doi.org/10.1063/1.5067350 